\title{
Cancer patients diagnosed with COVID-19 infection: a multicenter retrospective cohort of nine Brazilian cancer centers
}

\author{
Pacientes oncológicos com diagnóstico de infecção por COVID-19: uma coorte \\ retrospectiva multicêntrica de nove centros oncológicos brasileiros
}

Mariana Ribeiro Monteiro ${ }^{1,2 *}$, Kaique Ferreira Costa de Almeida ${ }^{1,2}$, Ana Beatriz Kinupe Abrahão ${ }^{1,2}$, Camila Brambilla de Souza ${ }^{1,2}$, Rafael Luis Moura Lima do Carmo 2,3, Maria Clara Borges de Andrade 4,5, Tuane Borges do Livramento Freitas ${ }^{4,5}$, Cecilia Lameirinhas Longo ${ }^{4,5}$, Maria Carolina Lopes Perdigão ${ }^{4,5}$, Cynthia Lemos Ferreira ${ }^{1,2}$, Tercia Tarciane Soares de Sousa ${ }^{1,2}$, Angelo Maiolino ${ }^{4,5}$, Sueli Monterroso da Cruz ${ }^{1,2}$, Gustavo Henrique Munhoz Piotto ${ }^{1,2}$, Fernando Meton de Alencar Camara Vieira ${ }^{4,5}$, Luiz Henrique Araujo $0^{4,5}$

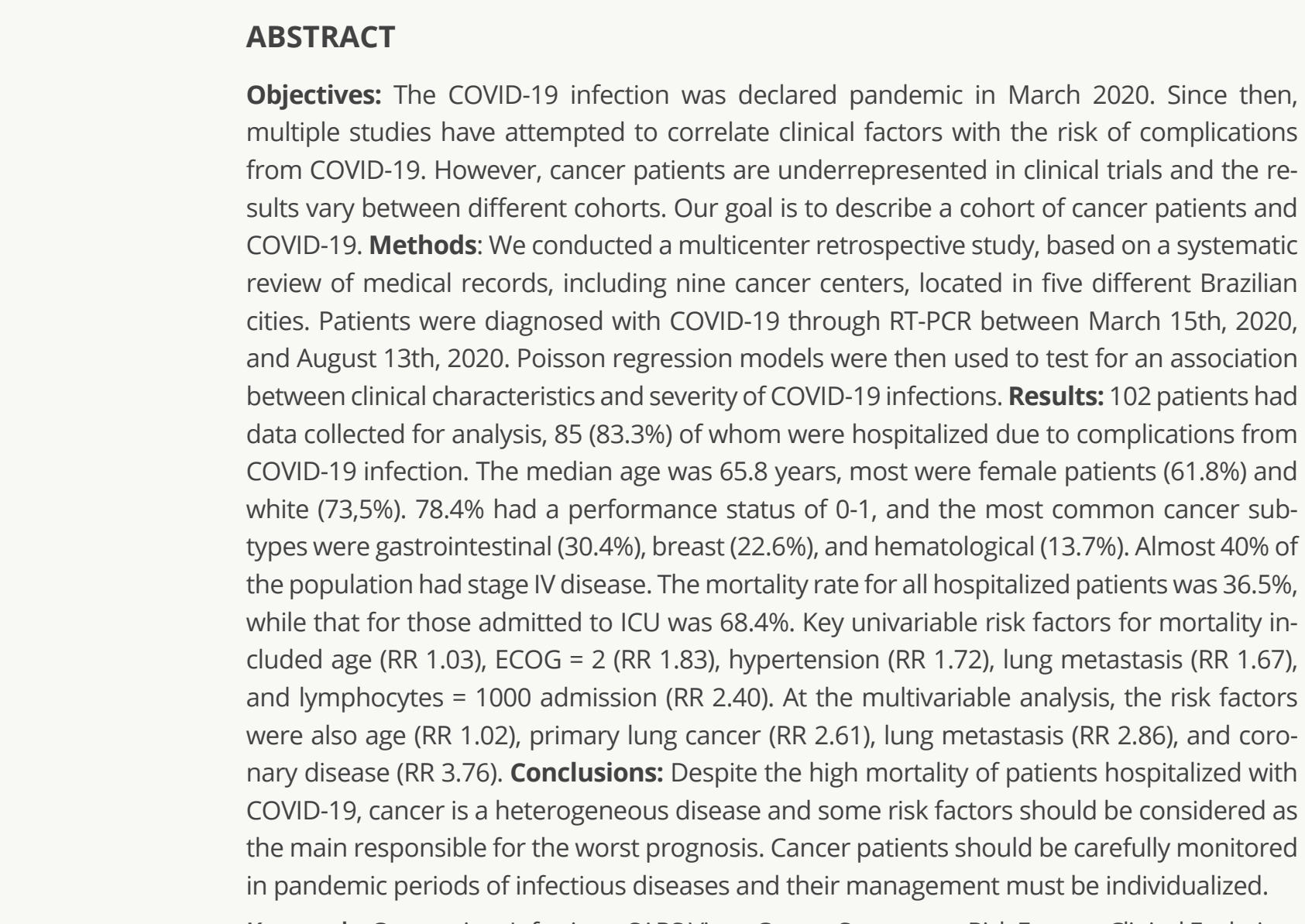

Keywords: Coronavirus Infections. SARS Virus. Cancer Symptoms. Risk Factors. Clinical Evolution.

1. Instituto COI de Educação e Pesquisa, Oncology Department, São Paulo - SP, Brazil.

2. Americas Centro de Oncologia Integrado, Oncology Department, São Paulo - SP, Brazil.

3. Radium Instituto de Oncologia, Medical Oncology - Campinas - SP, Brazil.

4. Instituto COI de Educação e Pesquisa, Oncology Department, Rio de Janeiro - RJ, Brazil.

5. Americas Centro de Oncologia Integrado, Oncology Department, Rio de Janeiro - RJ, Brazil.

Financial support: none to declare.

Conflicts of interest: The authors declare no conflict of interest relevant to this manuscript.

Correspondence author: Mariana Ribeiro Monteiro, Instituto COI de Educação e Pesquisa, Oncology Department, São Paulo - SP, Brazil.

E-mail: marianarmonteiro@hotmail.com 


\section{RESUMO}

Objetivos: A infecção pela COVID-19 foi declarada pandêmica em março de 2020. Desde então, vários estudos tentaram correlacionar fatores clínicos com risco de complicações pela COVID-19. No entanto, os pacientes com câncer estão sub-representados nos ensaios clínicos e os resultados variam entre as diferentes coortes. Nosso objetivo é descrever uma coorte de pacientes com câncer e COVID-19. Métodos: Foi realizado um estudo retrospectivo multicêntrico, baseado em revisão sistemática de prontuários médicos, incluindo nove centros oncológicos, localizados em cinco diferentes cidades brasileiras. Os pacientes foram diagnosticados com COVID-19 por RT-PCR entre 15 de março de 2020 e 13 de agosto de 2020. Modelos de regressão de Poisson foram então usados para testar a associação entre as características clínicas e a gravidade das infecções pela COVID-19. Resultados: 102 pacientes tiveram os dados coletados para análise, 85 (83,3\%) dos quais foram hospitalizados devido a complicações da infecção pela COVID-19. A mediana de idade foi de 65,8 anos, a maioria era do sexo feminino $(61,8 \%)$ e da cor branca $(73,5 \%) .78,4 \%$ tinham performance status de $0-1$, e os subtipos de câncer mais comuns foram gastrointestinal $(30,4 \%)$, mama $(22,6 \%)$ e hematológico $(13,7 \%)$. Quase $40 \%$ da população tinha doença em estágio IV. A mortalidade para todos os pacientes internados foi de $36,5 \%$, enquanto a dos internados em UTI foi de $68,4 \%$. Os principais fatores de risco univariados para mortalidade incluíram idade (RR 1,03), ECOG 22 (RR 1,83), hipertensão (RR 1,72), metástase pulmonar (RR 1,67) e na admissão linfócitos $\leq 1.000$ (RR 2,40). Na análise multivariável, os fatores de risco também foram idade (RR 1,02), câncer primário de pulmão (RR 2,61), metástase pulmonar (RR 2,86) e doença coronariana (RR 3,76). Conclusão: Apesar da alta mortalidade dos pacientes internados com COVID-19, o câncer é uma doença heterogênea e alguns fatores de risco devem ser considerados como os principais responsáveis pelo pior prognóstico. Pacientes com câncer devem ser cuidadosamente monitorados em períodos de pandemia de doenças infecciosas e seu manejo deve ser individualizado.

Descritores: Infecções por Coronavírus; Vírus SARS; Sintomas do câncer; Fatores de risco; Evolução Clínica.

\section{INTRODUCTION}

The infection caused by the novel coronavirus-19 (COVID-19) has emerged in December 2019 and was declared pandemic in March 2020.[1] The clinical presentation ranges between asymptomatic and acute respiratory syndrome and death. ${ }^{[2]}$ Because of their systemic inflammatory status and high prevalence of associated comorbidities, cancer patients are more susceptible to infections regardless of the natural course of disease and anticancer treatments. Moreover, the heterogeneity of this population makes it difficult to identify which are the most prevalent and the important risk factors associated with outcomes during COVID-19 infection. ${ }^{[3]}$ Early reports from China showed that comorbidities such as hypertension, diabetes, and obesity were risk factors for COVID-19 mortality. Several clinical trials have also confirmed that cancer patients are at risk for worse outcomes as well. Among patients with cancer, those with higher ECOG PS, lung or hematological neoplasms and those with recent systemic treatment, appear to have higher risk of mortality. Smoking status, number of comorbidities, and older age are also risk factors. ${ }^{[4-9]}$ However, it is noticed that many characteristics vary between different cohorts, therefore each cancer center should better study its population.

To date, few data exist regarding COVID-19 infection in patients with cancer in South America and the associations between outcomes and risk factors should be described. This is a retrospective and multicenter analysis of cancer patients, treated in nine private oncology centers in Brazil, describing association between demographic characteristics, risk factors, and clinical outcomes.

\section{MATERIAL AND METHODS}

\section{Study design and participants}

We conducted a multicenter, retrospective study, based on systematic review of medical records. The study population consisted of cancer patients treated in nine private centers belonging to Americas Oncologia, located in five different Brazilian cities, who were diagnosed with COVID-19 between March 
$15^{\text {th }}, 2020$ and August $13^{\text {th }}, 2020$. These patients could be diagnosed on an outpatient or inpatient basis. However, outpatients have not been identified systematically due to the low availability of RT-PCR testing and barriers to screening. Inpatients were identified by database from the Department of Epidemiology and Infection Control of the included institutions. All patients diagnosed with cancer, who were undergoing an active treatment or follow-up and, who had sufficient data for collection could be included. We enrolled patients with 18 years of age or older, with COVID-19 infection confirmed by reverse-transcription polymerase chain reaction (RT-PCR) on nasopharyngeal swab. Exclusion criteria were patients without cancer diagnosis, RTPCR negative for SARS-CoV-2, patients with clinical and radiological suspicion but RT-PCR negative, and patients without consistent data in medical records. The study was approved by regional ethical committee and was conducted according to the declaration of Helsinki.

\section{Data access}

An electronic form was prepared to collect patient's information including demographic data, cancer diagnosis, oncological treatment, and clinical conditions related to COVID-19 infection, preexistent comorbidities, medicine use, and outcomes. Patients were divided into subgroups according to their primary tumor site, such as hematological, gastrointestinal, breast, chest, and urological tumors. Staging was divided into groups I to IV according to AJCC $8^{\text {th }}$ edition. Regarding cancer treatment, patients could be on active treatment (chemotherapy, targeted therapy, immunotherapy or hormonal treatment) or follow-up, with or without evidence of active disease. Data on the last treatment performed, history of radiation therapy, surgery, and bone marrow transplantation were collected and described. During the course of COVID-19 infection, all procedures performed, including laboratory tests and concomitant medications, were analyzed.

\section{Statistical analysis}

Patients' demographics and clinical characteristics were reported as frequencies (proportions) for categorical variables and median for continuous variables. Data were described using absolute and percentage frequencies (qualitative variables) and through measures such as mean, standard deviation, median, quartiles, minimum and maximum (quantitative variables). We described baseline epidemiological data divided into two groups: the group of inpatients and the total population. For the analysis of risk factor for mortality, we evaluated only the population that was hospitalized, to reduce selection bias. Comorbidities known as risk factors and treatments that could potentially affect outcomes were included. For smoking status, never smoker was defined as an individual who smoked less than 100 cigarettes in lifetime. Former smoker included patients who had quit smoking for at least 12 months before inclusion.

Poisson regression models were then used to test for an association between outcome measure (death due to COVID-19) and clinical characteristics. We chose this method because it provides a risk ratio (RR) - which is easier to interpret -, and robust error estimation that ensure accurate inference. ${ }^{[10]}$ Next, we assessed whether there was evidence of effect modification on an additive scale by examining how the association between clinical variables and COVID-19 differed across strata of known cancer and COVID-19 risk factors: age, gender, location of metastasis, lung and hematological cancer, number of lymphocytes, cardiovascular comorbidities, chronic obstructive pulmonary disease (COPD), diabetes, Eastern Cooperative Oncology Group (ECOG) performance status (PS), systemic treatment, intensive care unit (ICU) admission, and dialysis. We used Poisson regression models to examine the association between clinical characteristics and COVID-19 mortality across all the categories.

The analysis of the relationship between the variables of interest and the length of stay was performed using a multiple linear regression model. In order to correlate risk factors with mortality, we excluded outpatients, as the better prognosis of this population could lead to bias.

\section{Outcomes}

The primary endpoint of the study was the mortality rate of inpatients with cancer and COVID-19. Secondary endpoints included the association between tumor subtype, recent chemotherapy, comorbidities, and location of metastasis with allcause mortality and the association between clinical findings and length of hospital stay.

\section{RESULTS}

At the data of cutoff we had 130 oncologic patients eligible for analysis. Five patients who were transferred to hospices and 17 patients without available outcomes were also excluded from the final analysis. Six patients with negative RT-PCR for SARS-CoV-2 were not included. Finally, association between risk factor and mortality was performed in 85 patients, which corresponded to hospitalized patients (Figure 1).

\section{Baseline characteristics}

One hundred and two patients were included, and of these, 85 were hospitalized and had their data collected for analysis of risk factors. Baseline characteristics are summarized in Tables 1, 2, and 3. The median age in the entire population was 65.8 years, most were female patients (61.8\%) and white (73.5\%). Most patients had good PS, including $78.4 \%$ patients with ECOG PS 0-1. The main comorbidities were arterial hypertension (45.0\%) and diabetes (31.4\%). However, $77.4 \%$ of patients had some 


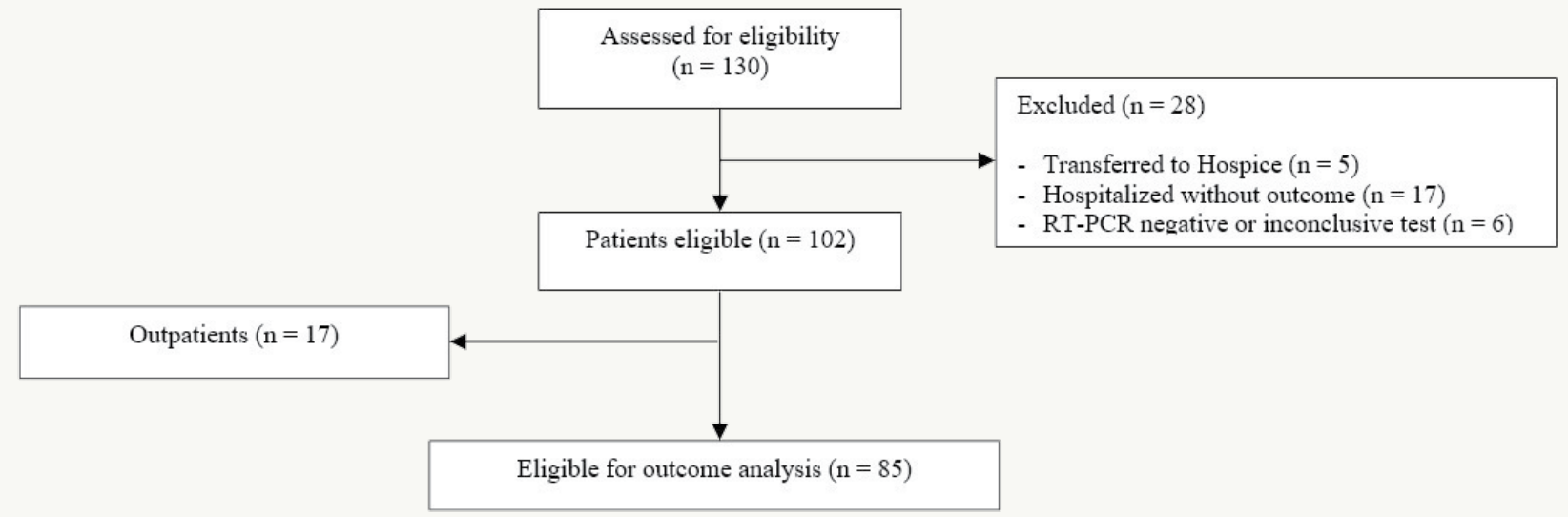

Figure 1. Flow diagram for study selection.

type of comorbidities, including chronic obstructive pulmonary disease (COPD), coronary disease, hypothyroidism, other pulmonary pathologies, obesity, among others. Of those patients with a history of smoking, 38.2\% were current or former smokers. Obesity was present in $24.5 \%$ of the cohort (Table 1).

Among tumor characteristics, patients with solid and hematological tumors comprised $88.3 \%$ and $13.7 \%$ of the population, respectively. The most common types of cancer were gastrointestinal (30.4\%), breast $(22.5 \%)$, and hematological (13.7\%). Patients with urological and thoracic tumors comprised $9.8 \%$ of the population each. Almost $40 \%$ of the population had stage IV disease (Table 2).

Regarding cancer treatment, about half of patients were undergoing some type of systemic treatment. Of these, a high proportion of patients undergoing treatment with palliative intent was found in the cohort of hospitalized patients (84.7\%). Among patients who were on endocrine therapy, most were not hospitalized. Less than a third of the patients had undergone any local treatment, such as surgery or radiation therapy. And finally, only 4 patients underwent bone marrow transplantation, all of whom were hospitalized during the course of COVID-19 (Table 3).

\section{Clinical evolution during COVID-19 infection}

Of the cohort patients who were hospitalized, 38 (44.7\%) were referred to the ICU. The median length of hospital stay was 12 days in both cases. For those patients admitted at ICU, the median length under intensive care was also 12 days. Five patients (5.9\%) were not referred to the ICU because they were in palliative/end-of-life care, as part of the medical and patient or family decision. Regarding the intensive supportive care performed, 29 (34.1\%) required invasive mechanical ventilation, 8 (9.4\%) tracheostomy, 11 (12.9\%) dialysis, and 15 (17.6\%) prone. Only one patient was enrolled in a clinical trial for COVID-19, which involved convalescent plasma infusion. All of these results are summarized in Table 4.

\section{Outcomes}

The primary objective of the study was to assess the mortality rate of inpatients with cancer and COVID-19. The results in the total hospitalized population and in those who were referred to the ICU are described in Table 5. The mortality rate for all hospitalized patients was $36.5 \%$, while that for those admitted to the ICU was $68.4 \%$.

We also aimed to assess variables that could increase the risk of death due to COVID-19 in cancer patients. In Table 6 and Figure 2 we present the results of the univariate analyzes and those adjusted according to multiple risk factors. Key univariable baseline risk factors for mortality due to COVID-19 in patients with cancer included: age at the onset of symptoms (RR 1.03), ECOG $\geq 2$ (RR 1.83), arterial hypertension (RR 1.72), lung metastasis versus none ( $R R$ 1.67), lymphocytes $\leq 1,000$ (RR 2.40 ), and neutrophil-to-lymphocyte ratio $\geq 4$ (RR 2.25 ) at the hospital admission. Regarding the variables during the course of hospitalization, every three days hospitalized increases the risk by 5\% (RR 1.05), as well as the admission in the ICU (RR 3.43), mechanical ventilation (RR 3.85), tracheostomy (RR 1.78), dialysis (RR 2.74), and prone (RR 2.60). After multivariable adjustment for the main clinical factors, the risk factors for death were age at the onset of the symptoms (RR 1.02), primary lung cancer (RR 2.61), lung metastasis versus none (RR 2.86), and coronary disease (RR 3.76). Among the hospitalization variables, ICU admission (RR 5.77) and end-of-life care in the palliative setting (RR 6.41) continued to be an important issue. Figure 2 outlines the results of the univariate and multivariate analyzes in a forest plot diagram.

As a secondary endpoint, we aimed to evaluate the association between clinical characteristics and length of hospital stay. However, the only variables that significantly increased length of stay were ICU admission and tracheostomy. Comorbidities, metastatic disease, number of lymphocytes, ECOG $\geq 2$ or systemic treatment were not responsible for longer hospitalization (Table 7). 
Table 1. Baseline characteristics in all cohort and hospitalized patients.

\begin{tabular}{|c|c|c|}
\hline Variable & All patients $(\mathrm{N}=102)$ & Inpatients (N=85) \\
\hline \multicolumn{3}{|l|}{ Demographic factors } \\
\hline Median age & $65,8(53,6-75,4) N(\%)$ & $68,1(55,3-76,7) \mathrm{N}(\%)$ \\
\hline \multicolumn{3}{|l|}{ Gender } \\
\hline - Male & - $39(38.2 \%)$ & - $35(41.2 \%)$ \\
\hline - Female & $-63(61.8 \%)$ & $-50(58.8 \%)$ \\
\hline \multicolumn{3}{|l|}{ Ethnicity } \\
\hline - White & - $75(73.5 \%)$ & - $62(72.9 \%)$ \\
\hline - Afrodescendant & - $7(6.8 \%)$ & $-5(5.9 \%)$ \\
\hline - Unknown & $-20(19.6 \%)$ & $-18(21.2 \%)$ \\
\hline \multicolumn{3}{|l|}{ Clinical factors } \\
\hline \multicolumn{3}{|c|}{ Performance status (ECOG) } \\
\hline-0 & - $55(53.9 \%)$ & $-43(50.6 \%)$ \\
\hline-1 & $-25(24.5 \%)$ & $-21(24.7 \%)$ \\
\hline-2 & $-9(8.8 \%)$ & $-9(10.6 \%)$ \\
\hline-3 & $-6(5.9 \%)$ & $-5(5.9 \%)$ \\
\hline - Unknown & - $7(6.9 \%)$ & - $7(8.2 \%)$ \\
\hline \multicolumn{3}{|l|}{ Body mass index (BMI) } \\
\hline$-<18,5$ & $-5(4.9 \%)$ & $-4(4.7 \%)$ \\
\hline$-18,6-24,9$ & - $28(27.4 \%)$ & - $26(30.6 \%)$ \\
\hline$-25-29,9$ & - $40(39.2 \%)$ & - $31(36.5 \%)$ \\
\hline$-30-34,9$ & $-16(15.7 \%)$ & $-12(14.1 \%)$ \\
\hline$-35-39,9$ & $-6(5.9 \%)$ & $-5(5.9 \%)$ \\
\hline$-\geq 40$ & $-3(2.9 \%)$ & - $3(3.5 \%)$ \\
\hline - Unknown & $-4(3.9 \%)$ & $-4(4.7 \%)$ \\
\hline \multicolumn{3}{|l|}{ Smoking status } \\
\hline - Current smoker & $-8(7.8 \%)$ & - $8(9.4 \%)$ \\
\hline - Former smoker & - $31(30.4 \%)$ & - $26(30.6 \%)$ \\
\hline - Never smoker & $-44(43.1 \%)$ & $-32(37.6 \%)$ \\
\hline - Unknown & - $19(18.6 \%)$ & - $19(22.3 \%)$ \\
\hline \multicolumn{3}{|l|}{ Comorbidities } \\
\hline - COPD & - $13(12.7 \%)$ & $-12(14.1 \%)$ \\
\hline - Hypertension & - $46(45.0 \%)$ & $-41(48.2 \%)$ \\
\hline - Diabetes & - $32(31.4 \%)$ & - $31(36.5 \%)$ \\
\hline - Obesity & - $14(13.7 \%)$ & - $11(12.9 \%)$ \\
\hline - Coronary disease & $-9(8.8 \%)$ & $-7(8.2 \%)$ \\
\hline
\end{tabular}

\section{DISCUSSION}

In this multicenter retrospective study involving cancer patients with COVID-19 infection, we found higher mortality among patients in ICU compared with those treated on the ward. The median admission time in ICU was 12 days, which was the same length time of all admission period for less serious infection. Patients in end-of-life care at the palliative unit, ICU admission, and mechanical ventilation were the most important hospitalization variables to increase mortality. The presence of coronary disease was the most important patient comorbidity to increase the risk of death. Regarding cancer characteristics, although primary lung cancer increased the risk of death, patients with metastatic disease in the lungs had an even worse outcome. The mortality rate of cancer inpatients was our primary endpoint, and it was slightly higher than other international reports, but it was similar to that observed in Brazilian cohorts. 
Table 2. Tumor characteristics.

\begin{tabular}{lcc}
\hline Variable & All patients (N=102) & Inpatients (N=85) \\
\hline Type of cancer & $-88(86.3 \%)$ & $-73(85.9 \%)$ \\
- Solid & $-14(13.7 \%)$ & $-12(14.1 \%)$ \\
- Hematologic & $-5(4.9 \%)$ & $-5(5.9 \%)$ \\
Subtype & $-10(9.8 \%)$ & $-9(10.6 \%)$ \\
- Head and neck & $-5(4.9 \%)$ & $-4(4.7 \%)$ \\
- Urologic & $-14(13.7 \%)$ & $-12(14.1 \%)$ \\
- Gynecologic & $-23(22.5 \%)$ & $-16(18.8 \%)$ \\
- Hematologic & $-2(2.0 \%)$ & $-2(2.3 \%)$ \\
- Breast & $-1(1.0 \%)$ & $-0(0)$ \\
- Occult primary & $-1(1.0 \%)$ & $-1(1.2 \%)$ \\
- Central nervous system & $-31(30.4 \%)$ & $-27(31.8 \%)$ \\
- Sarcoma & $-10(9.8 \%)$ & $-9(10.6 \%)$ \\
- Gastrointestinal & & $-8(9.4 \%)$ \\
- Thoracic & $-15(14.7 \%)$ & $-9(10.6 \%)$ \\
Staging & $-9(8.8 \%)$ & $-19(22.3 \%)$ \\
- I & $-22(21.6 \%)$ & $-35(41.2 \%)$ \\
- II & $-40(39.2 \%)$ & $-14(16.5 \%)$ \\
- III & $-16(15.7 \%)$ & \\
- IV & & \\
- Unknown/not applicable & & $-12 \%$ \\
\hline
\end{tabular}

Table 3. Oncological treatment.

\begin{tabular}{lcc}
\hline Variable & All Patients (N=102) & Inpatients (N=85) \\
\hline Systemic treatment & & $-25(29.4 \%)$ \\
- Chemotherapy & $-33(32.3 \%)$ & $-3(3.5 \%)$ \\
- Immunotherapy & $-5(4.9 \%)$ & $-10(1.2 \%)$ \\
- Target therapy & $-10(9.8 \%)$ & $-3(3.5 \%)$ \\
- Endocrine therapy & $-14(13.7 \%)$ & $-1(1.2 \%)$ \\
- Other & $-2(2.0 \%)$ & $-39(45.9 \%)$ \\
- None & $-45(44.1 \%)$ & $-49(57.6 \%)$ \\
Treatment goal & & $-36(42.3 \%)$ \\
- Curative & $-62(60.8 \%)$ & $-14(16.5 \%)$ \\
- Palliative & $-40(39.2 \%)$ & $-7(8.2 \%)$ \\
Treatment performed in the last 12 months & & $-18(21.2 \%)$ \\
- Radiotherapy & $-19(18.6 \%)$ & $-4(4.7 \%)$ \\
- Thoracic radiotherapy & $-12(11.8 \%)$ & $-25(24.5 \%)$ \\
- Surgery & $-4(3.9 \%)$ & \\
- Bone marrow transplant & & \\
\hline
\end{tabular}

Table 4. Clinical course during hospitalization.

\begin{tabular}{lccc}
\hline Variables & $\mathbf{N}$ & \% & Median (days) \\
\hline Length of stay & 85 & 100 & $12(7-22)$ \\
Length of stay in the ICU & 38 & 44.7 & $12(6-29)$ \\
Patient who did not go to the ICU for being in palliative care & 5 & 5.9 & - \\
Mechanical ventilation & 29 & 34.1 & - \\
Tracheostomy & 8 & 9.4 & - \\
Dialysis & 11 & 12.9 & - \\
Prone & 15 & 17.6 & - \\
Clinical protocol for COVID-19 treatment & 1 & 1.2 & - \\
\hline
\end{tabular}


Table 5. Mortality rate at data cutoff.

\begin{tabular}{lcc}
\hline Variable & N & $\begin{array}{c}\text { Number of } \\
\text { deaths (\%) }\end{array}$ \\
\hline Inpatients & 85 & $31(36.5 \%)$ \\
ICU patients & 38 & $26(68.4 \%)$ \\
Palliative/end-of-life care & 5 & $5(100 \%)$ \\
\hline
\end{tabular}

A trial developed by the Brazilian National Cancer Institute, which included 181 hospitalized cancer patients, reported a mortality rate of $33.1 \%$. Patients with older age, lung or bone metastasis, and two or more metastatic sites had higher risk. ${ }^{[11]}$ The rate of patients admitted to the ICU in this cohort was $17.1 \%$, compared to $44.7 \%$ in our study. This data could be partially explained by the different populations,

Table 6. All cause fatality risk after COVID-19 by clinical characteristics.

\begin{tabular}{|c|c|c|c|c|}
\hline \multirow{2}{*}{ Clinical characteristics } & \multicolumn{2}{|c|}{ Univariate analysis } & \multicolumn{2}{|c|}{ Multivariate analysis } \\
\hline & RR (IC 95\%) & p-value & RR (IC 95\%) & p-value \\
\hline Age at the onset of symptoms & $1.04(1.01-1.05)$ & $<0,01 * \star$ & $1.02(1.01-1.04)$ & $<0,01 * *$ \\
\hline Male gender & $1.04(0.64-1.68)$ & 0,88 & $0.90(0.55-1.48)$ & 0,68 \\
\hline Lung cancer & $1.28(0.68-2.42)$ & 0,45 & $2.61(1.40-4.87)$ & $<0,01 * *$ \\
\hline Lung metastasis & $1.95(1.17-3.26)$ & $0,01 * *$ & $2.86(1.73-4.73)$ & $<0,01 * \star$ \\
\hline Lymphocytes <1,000 & $2.40(1.14-5.03)$ & $0,02 * \star$ & $0.98(0.58-1.67)$ & 0,94 \\
\hline$N L R \geq 4$ * & $2.25(1.18-4.27)$ & $0,01 * \star$ & $1.35(0.77-2.38)$ & 0,3 \\
\hline PLR $\geq 126,7$ * & $1.31(0.71-2.41)$ & 0,4 & - & - \\
\hline G-CSF * use (last 14 days) & $1.11(0.40-3.05)$ & 0,84 & - & - \\
\hline Comorbidities & $1.62(0.75-3.53)$ & 0,22 & - & - \\
\hline - Hypertension & $1.72(1.04-2.86)$ & $0,04 * *$ & $0.98(0.55-1.75)$ & 0,94 \\
\hline - Diabetes & $1.45(0.91-2.33)$ & 0,12 & $1.10(0.55-2.20)$ & 0,78 \\
\hline - Obesity & $1.04(0.52-2.08)$ & 0,92 & - & - \\
\hline - Coronary disease & $1.33(0.67-2.66)$ & 0,41 & $3.76(1.56-9.07)$ & $<0,01 * *$ \\
\hline - COPD* & $1.40(0.81-2.43)$ & 0,23 & $0.52(0.26-1.02)$ & 0,06 \\
\hline$E C O G \geq 2 *$ & $1.83(1.16-2.87)$ & $<0,01 * *$ & $1.33(0.85-2.06)$ & 0,21 \\
\hline Systemic treatment & $0.66(0.40-1.09)$ & 0,11 & $0.81(0.43-1.51)$ & 0,5 \\
\hline Current/former smoker & $0.88(0.53-1.47)$ & 0,63 & - & - \\
\hline Length of stay (every 3 days) & $1.05(1.00-1.10)$ & $0,04 * \star$ & - & - \\
\hline ICU admission* & $3.43(1.91-6.15)$ & $<0,01 * \star$ & $5.77(2.41-13.85)$ & $<0,01$ ** \\
\hline End-of-life care & $2.35(1.64-3.35)$ & $<0,01 * *$ & $6.41(2.65-15.47)$ & $<0,01 * *$ \\
\hline Mechanical ventilation & $3.85(2.35-6.30)$ & $<0,01 * *$ & - & - \\
\hline Tracheostomy & $1.78(1.10-2.88)$ & $0,02 * \star$ & - & - \\
\hline Dialysis & $2.74(2.03-3.70)$ & $<0,01$ ** & $1.24(0.60-2.57)$ & 0,56 \\
\hline Prone & $2.60(1.75-3.86)$ & $<0,01 * *$ & - & - \\
\hline
\end{tabular}
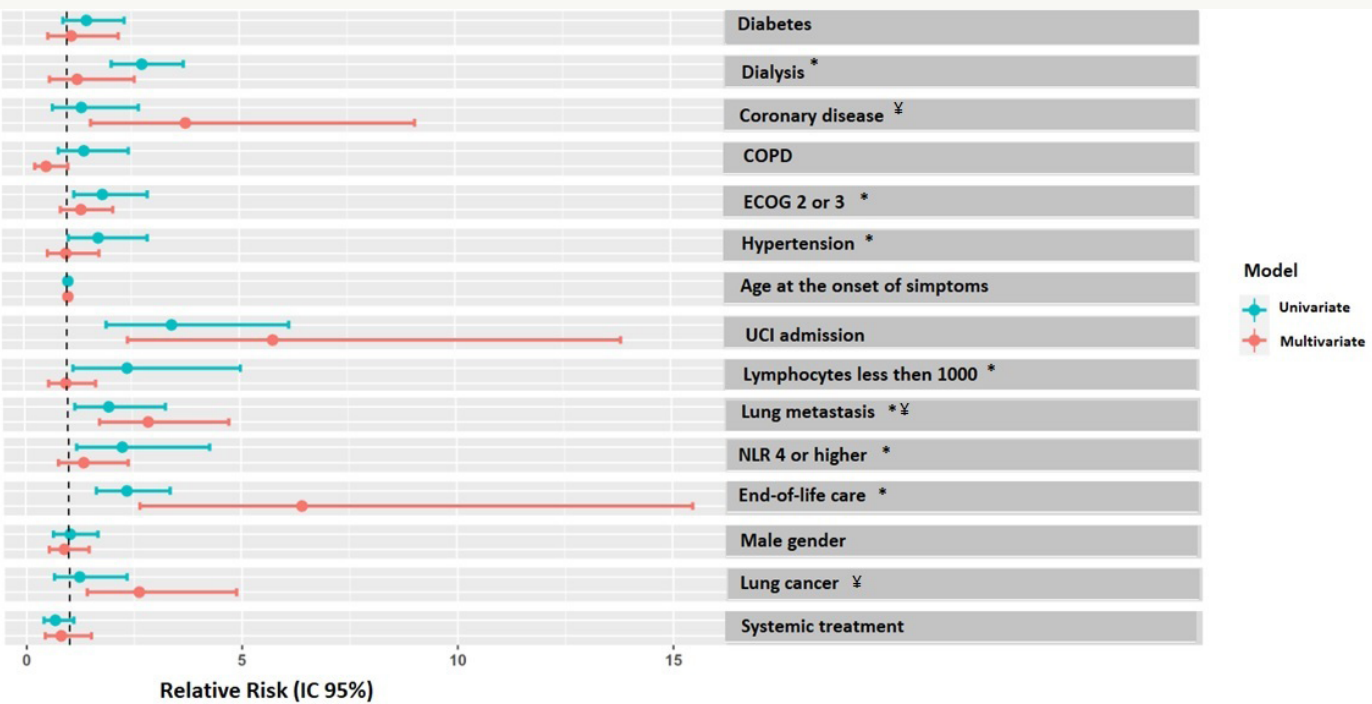

Figure 2. Forest plot diagram describing association between the main clinical variables and all-cause mortality rate during COVID-19 infection. *Variables with significance at univariate analysis; ¥: Variables with significance at multivariate analysis. 
Table 7. Mean difference in median length of stay according to clinical variables.

\begin{tabular}{lccc}
\hline Variables & Estimated mean difference & IC 95\% & p-value \\
\hline Presence of metastasis & 0.33 & $-0.11-0.77$ & 0,77 \\
Lung cancer & -0.20 & $-0.90-0.49$ & 0,56 \\
Lymphocytes $\leq 1,000$ & -0.05 & $-0.60-0.50$ & 0,86 \\
NLR $\geq 4^{*}$ & -0.06 & $-0.61-0.48$ & 0,81 \\
Comorbidities & 0.42 & $-0.10-0.94$ & 0,11 \\
ECOG $\geq 2^{*}$ & -0.26 & $-0.85-0.33$ & 0,38 \\
Systemic treatment & 0.26 & $-0.17-0.69$ & 0,22 \\
ICU admission* & 0.91 & $0.04-1.79$ & $0,04^{* *}$ \\
Mechanical ventilation & -0.96 & $-2.02-0.10$ & 0,07 \\
Tracheostomy & 1.37 & $0.54-2.20$ & $<0,01 * *$ \\
Dialysis & 0.45 & $-0.34-1.25$ & 0,26
\end{tabular}

*NLR = Neutrophil-to-lymphocyte ratio; ECOG = Eastern cooperative oncology group performance status; ICU = Intensive care unit; ${ }^{* *} p<0,05$ were considered statistically significant.

including the distinct severity of the disease. Data from a single-center Brazilian hospital in São Paulo, presented at the ESMO (European Society of Medical Oncology) 2020 Congress evaluated a cohort of cancer patients diagnosed with COVID-19. Overall mortality rate was $40.95 \%$. Of the 105 patients, $69.52 \%$ required hospitalization and $33.3 \%$ were referred to the ICU. ${ }^{[12]}$ More recently, a broader study conducted in private practices in Brazil showed a mortality rate of $16.7 \%$ among 198 cancer patients. However, it is a cohort of patients with better prognosis, including $29 \%$ of patients with breast cancer, 35\% undergoing curative treatment, and $55 \%$ of outpatients. ${ }^{[13]}$

Early Chinese data, in an unselected population, showed a mortality rate by $30 \%$ for patients with severe disease and more than $80 \%$ for those admitted to the ICU. Median duration of hospitalization was 12 days, also similar to our data. ${ }^{8]}$ Importantly, our hospitals provide cancer care at the tertiary level, with advanced diagnostic and treatment support, which can increase incidence of serious cases.

There is limited data on the incidence of COVID-19 in cancer patients. The Department of Radiation and Medical Oncology of Zhongnan Hospital of Wuhan University have published a cohort of 1,524 cancer patients, of which $12(0.79 \%)$ had COVID-19, versus $0.37 \%$ of the general population of Wuhan during the same period of time (OR 2.31, 95\% Cl: 1.89-3.02). ${ }^{[14]}$ Approximately 1,630 cancer patients are treated each month at our cancer centers. Considering that almost 8,150 patients are treated in the nine cancer centers during the study inclusion period, we can estimate that nearly $1.04 \%$ of our population had an indication for hospitalization due to COVID-19 complications during this pandemic period. The Chinese retrospective trial appeared to have a cohort of patients with a worse prognosis, 58.3\% of whom had lung cancer. Other Chinese studies also shows a higher prevalence of lung cancer and a propensity to worse outcomes, particularly in patients who underwent chemotherapy in the last 14 days and those with older age. ${ }^{[15,16]}$ Another Chinese case-control study of 232 cancer patients, conducted in nine hospitals in Wuhan, showed a higher risk of complications compared to patients without cancer. Those with ECOG $>2$, advanced disease, recent antitumor treatment, and elevated pro-inflammatory peptides are at increased risk for severe disease. ${ }^{[17]}$ Unlike our study, hypertension and coronary heart disease did not lead to a higher risk and the impact of lung cancer or lung metastases was not reported.

During the course of the pandemic, retrospective trials were also developed by many countries. A consort of more than 120 centers from US, Canada and Spain have published data on cancer patients and COVID-19. Of 928 patients, the most common types of cancer were breast $(21 \%)$ and prostate $(16 \%)$, however, it also included outpatients; therefore, it had a mortality rate of $13 \%$, lower than that observed in our study. Among the patients who required hospitalization, the mortality rate within 30 days of inclusion was $23 \%$. This rate may have been lower due to distinct population or shorter followup. Among risk factors for mortality, male gender, smoking status, ECOG, and number of comorbidities were responsible for worse outcomes. ${ }^{[9]}$

A multicenter, prospective study involving data collection from patients with thoracic malignancies included 200 patients, of whom 66 (33\%) died, whether hospitalized or at home. The risk factors were similar, including age and smoking status. ${ }^{[4]}$ In this study, it was also noticed that patients with thoracic tumors had a lower rate of admission to the ICU, and suggest that the indication of intensive care should be better discussed in view of therapeutic advances. This was not a challenge in our cohort as none of the patients not referred to the ICU had lung cancer, two of whom had no active cancer, but advanced age. The higher mortality rate for patients in palliative care, in general with more advanced tumors and older age, was also observed in other cohorts. ${ }^{[4,9]}$ A retrospective cohort from New York showed that, among 218 patients with a malignant diagnosis, the fatality rate was $28 \%$, particularly 
higher in lung and hematological malignancies. ${ }^{[18]}$ A single-center study from the UK Cancer Center reached a mortality rate of $22 \%$, however, $82 \%$ of the population had mild/moderate COVID-19. ${ }^{[19]}$

By using a multiple linear regression model, it was possible to analyze the relationship between length of stay and clinical variables. However, only variables related to the severity of COVID-19, such as ICU admission and tracheostomy, were associated with prolonged hospitalization.

The main strengths of our study is that it is a multicenter trial, which explores different levels of hospital care. The main limitations are the retrospective design, leading to missing data, and the absence of a comparator group of patients without cancer. In addition, there is a selection bias, represented by the low rate of outpatients, not reflecting the real incidence of COVID-19 in patients treated in our cancer centers.

Several studies involving the development of vaccines against COVID-19 infection are underway. As cancer patients are generally not included in these trials, many questions may arise regarding the risks and effectiveness of this type of prevention for cancer patients. Whereas more than 17 million patients are diagnosed with cancer every year worldwide, we must always consider cancer as pandemic and assess the possibility of including such patients in prospective trials. Currently, we also know that COVID-19 pneumonia can lead to chronic symptoms, many of which coincide with symptoms of cancer or its treatment. Longer follow-up may be necessary to better clarify the real impact of the pandemic on this population.

\section{CONCLUSION}

Despite the high mortality of patients hospitalized with COVID-19, our data are compatible with other Brazilian cohorts and with other risk groups. Cancer patients must be carefully monitored in pandemic periods of infectious diseases.

\section{ACKNOWLEDGEMENTS}

The author are grateful to all UnitedHealth Group professionals who worked on supportive care of cancer patients with COVID-19.

\section{REFERENCES}

1. World Health Organization (WHO). WHO DirectorGeneral's opening remarks at the media briefing on COVID-19 - 11 March 2020 [Internet]. Geneva: WHO; 2020; [access in 2020 Aug 26]. Available from: https://www.who.int/director-general/speeches/ detail/who-director-general-s-opening-remarks-atthe-media-briefing-on-covid-19---11-march-2020

2. Wu Z, McGoogan JM. Characteristics of and important lessons from the coronavirus disease 2019 (COVID-19) outbreak in China: summary of a report of 72314 cases from the Chinese Center for Disease Control and Prevention. JAMA. 2020 Feb;323(13):1239-42.
3. Dai M, Liu D, Liu M, Zhou F, Li G, Chen Z, et al. Patients with cancer appear more vulnerable to SARSCOV-2: a multi-center study during the COVID-19 outbreak. Cancer Discov. 2020 Jun;10(6):783-91.

4. Garassino MT, Whisenant JG, Huang LC, Trama A, Torri V, Agustoni F, et al. COVID-19 in patients with thoracic malignancies (TERAVOLT): first results of an international, registry-based, cohort study. Lancet Oncol. 2020 Jul;21(7):914-22.

5. Jee J, Foote MB, Lumish M, Stonestrom AJ, Wills B, Narendra V, et al. Chemotherapy and COVID-19 outcomes in patients with cancer. J Clin Oncol. 2020 Oct;38(30):3538-46.

6. Lee LYW, Cazier JB, Starkey T, Briggs SEW, Arnold R, Bisht V, et al. COVID-19 prevalence and mortality in patients with cancer and the effect of primary tumor subtype and patient demographics: a prospective cohort study. Lancet Oncol. 2020 Oct;21(10):1309-16.

7. Lee LY, Cazier JB, Angelis V, Arnold R, Bisht V, Campton NA, et al. COVID-19 mortality in patients with cancer on chemotherapy or other anticancer treatments: a prospective cohort study. Lancet. 2020 Jun;395(10241):1919-26.

8. Guan WJ, Ni ZY, Hu Y, Liang WH, Ou CQ, He JX, et al. Clinical characteristics of coronavirus disease 2019 in China. N Engl J Med. 2020 Apr;382:1708-20.

9. Kuderer NM, Choueiri TK, Shah DP, Shyr Y, Rubinstein SM, Rivera DR, et al. Clinical impact of COVID-19 on patients with cancer (CCC19): a cohort study. Lancet. 2020 Jun;395(10241):1907-18.

10. Zou G. A modified Poisson regression approach to prospective studies with binary data. Am J Epidemiol. 2004 Apr;159(7):702-6.

11. Melo AC, Thuler LCS, Silva JL, Albuquerque LZ, Pecego $A C$, Rodrigues LOR, et al. Cancer inpatient with COVID-19: a report from the Brazilian National Cancer Institute. PLoS One. 2020 Oct;15(10):e0241261.

12. Magalhaes M, Rego LA, Rebouças CV, Alves RB, Adami F, Cruz FJSM. Clinical and epidemiologic aspects of patients with cancer and COVID-19 in a Brazilian cancer center. Poster presented at ESMO 2020 Conference. Ann Oncol. 2020 Sep;31(Suppl 4):S1027. DOI: https://doi.org/10.1016/j.annonc.2020.08.1834

13. Ferrari BL, Ferreira CG, Menezes M, Marchi P, Canedo J, Melo AC, et al. Determinants of COVID-19 mortality in patients with cancer from o community oncology practice in Brazil. JCO Glob Oncol. 2021;7:46-55.

14. Yu J, Ouyang W, Chua MLK, Xie C. SARS-CoV-2 transmission in patients with cancer at a tertiary care hospital in Wuhan, China. JAMA Oncol. 2020 Jul;6(7):1108-10.

15. Zhang L, Zhu F, Xie L, Wang C, Wang J, Chen R, et al. Clinical characteristics of COVID-19-infected cancer patients: a retrospective case study in three hospitals within Wuhan, China. Ann Oncol. 2020 Jul;31(7):894-901. 
16. Liang W, Guan W, Chen R, Wang W, Li J, Xu K, et al. Cancer patients in SARS-CoV-2 infection: a nationwide analysis in China. Lancet Oncol. 2020 Mar;21(3):335-7.

17. Tian J, Yuan X, Xiao J, Zhang Q, Yang C, Liu B, et al. Clinical characteristics and risk factors associated with COVID-19 disease severity in patients with cancer in Wuhan, China: a multicentre, retrospective, cohort study. Lancet Oncol. 2020 Mar;21:893-903.
18. Mehta V, Goel S, Kabarriti R, Cole D, Goldfinger M, Acuna-Villaorduna A, et al. Case fatality rate of cancer patients with COVID-19 in a New York hospital system. Cancer Discov. 2020 Jul;10(7):935-41.

19. Russel B, Moss C, Papa S, Irshad S, Ross P, Spicer J, et al. Factors affecting COVID-19 outcomes in cancer patients: a first report from Guy's Cancer Center in London. Front Oncol. 2020 Jul;10:1279. 